" قابلية اختراعات التكذولوجيا الحيوية للحصول على براءة الاختراع "

\title{
The patentability of biotechnology inventions
}

Benayad Djalila

Faculty of Law and Political Science, University of Mhamed Bougherra ,Boumerdes, Algeria

DOI : doi.org/10.46617/icbe6012 ania-rose14@hotmail.fr

تعتبر التكنولوجيا الحيوية سمة الحياة المعاصرة فهي بمثابة الثورة العلمية الرابعة للقرن العشرين بعد ثورة تحطيم الذرة و الفضاء و الحاسب الآلي ، وان تطبيقاتها ليست مقتصرة على مجال معين و إنما تستخدم في جميع مجالات الحياة .

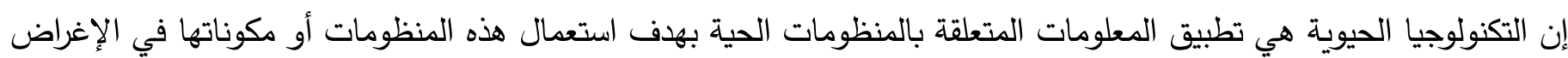

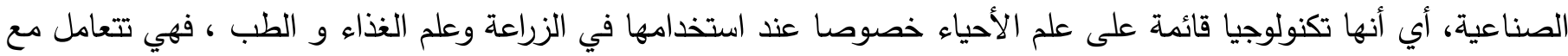

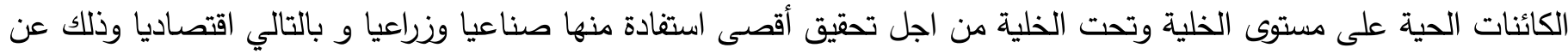
طريق تحسين خواصها وصفاتها الوراثية .

فباستخدام التكنولوجيا الحيوية ظهرت أدوية جديدة ،نباتات معدلة ، مواد عضوية طبيعية ، تطوير في الكائنات الحية البحرية ...الخ كل هذه الابتكارات يقوم باختراعها أشخاص يبرزون من خلالها جميع مواهبهم و إبداعاتهم لإخراجها في صورتها النهائية حتى تستقيد منها البشرية لذا فإنه كان لزاما وضع منظومة قانونية لحماية هذا النوع من الاختراعات ، هذا ما يجعلنا نبرز من خلال هذه الورقة البحثية الخصوصية التي تتمتع بها اختراعات التكنولوجيا الحيوية من حيث استيفائها للثروط الموضوعية لمنح البراءة . المحور الأول

\section{شروط حماية الاختراعات الحيوية و أهميتها}

إن الاختراعات الناتجة عن التكنولوجيا الحيوية شأنها شأن أي اختراع ، لابد أن تتوافر فيها شروط الحماية من جدة وخطوة إبداعية

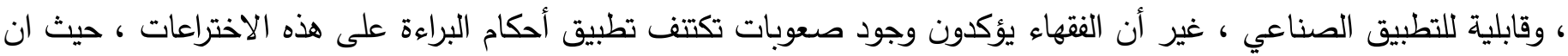
نظام الحماية عن طريق البراءة يفقد جزءا من خصوصيته بالنسبة للاختراعات الحيوية ، فالملائمة الكلية بين نظام البراءة واختراعات

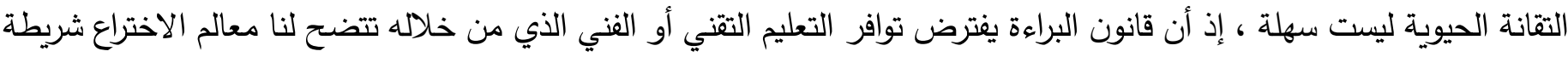

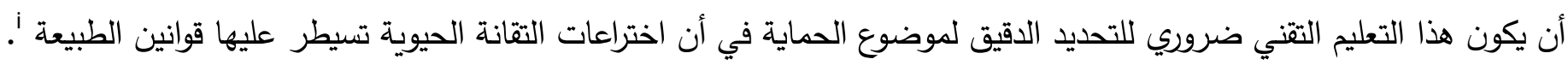
أولا: الثروط الموضوعية و الثكلية للحصول على براءة اختراع : لا يمكن استصدار براءة إلا إذا كان الاختراع مطابقا للشروط القانونية المنصوص عليها في الأمر 03/07 كانت موضوعية أو شكلية وعليه متى قام المخترع باحترام الثروط القانونية فإنه يتمتع بالحماية القانونية. 1

هي الثروط الواجب توافرها في موضوع البراءة المتمثل في الاختراع، وتمنح براءة الاختراع عن كل اختراع جديد ناتج عن نشاط اختراعي و قابل للاستغلال الصناعي،بما في ذلك الاختراعات المتعلقة بالتكنولوجيا الحيوية .

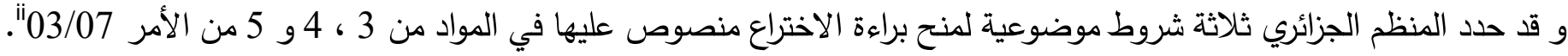
أ ـ ـ أن يكون الاختراع جديدا:

يشترط القانون أن يكون الاختراع المراد حمايته جديدا ، فالدولة كمبدأ عام لا تحمي المخترع إلا إذا قدم للمجتمع خدمة 


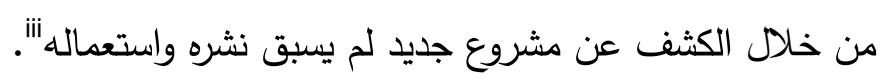

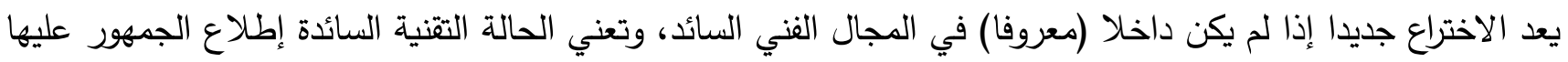
بكل وسائل الاتصال، ويترتب على ذلك أن الجدة مرتبطة ارتباطا جذريا مع السرية إذ لا يكون الاختراع جديدا ما لم يكن معروفا من

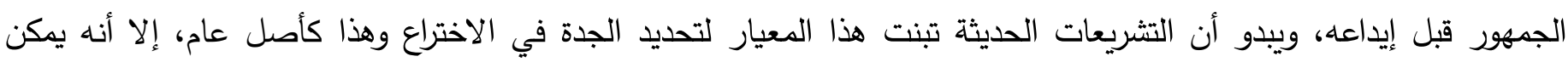
الاعتراف بالجدة على الرغم من نشر الاختراع وإطلاع الجمهور عليه وهذا كاستثاء وفي حالات محددة جاءت بالمادة 4 من الأمر

وعند الحديث عن توفر شرط الجدة في اختراعات التكنولوجيا الحيوية، فإن هذا الشرط يتصف بخصوصية معينة تبدو عند تحديد

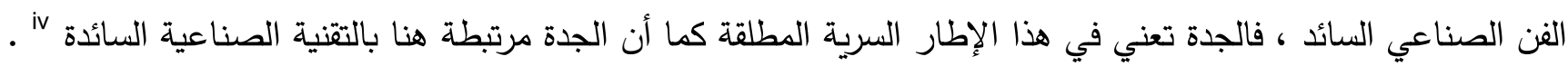

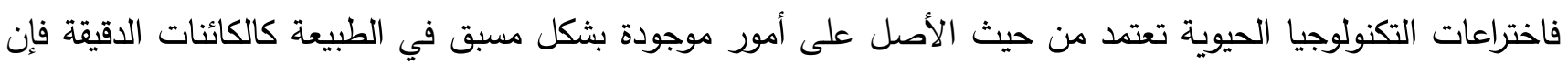

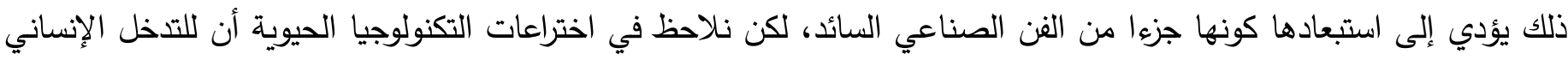

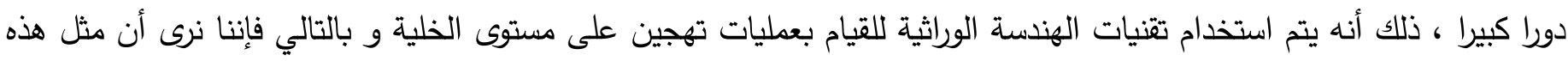

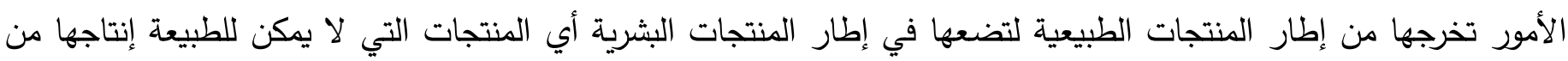

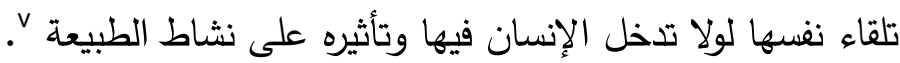
ب ـ ـ عدم البديهية والخطوة الإبتكارية: يفترض شرط الابتكار أن يكون الاختراع لثيء جديد لم يكن موجودا من قبل أو اكتثاف شيء كان موجودا ولكنه كان

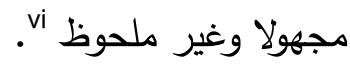

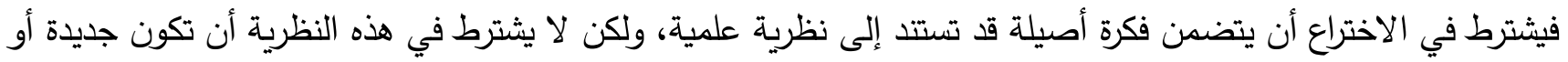

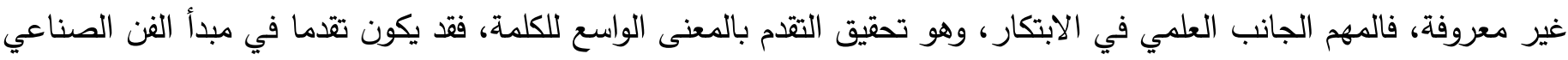

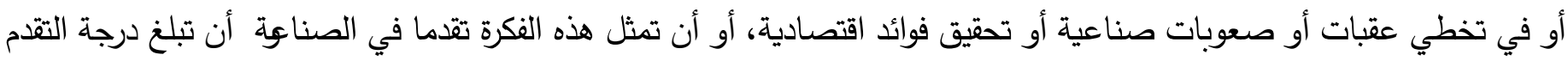

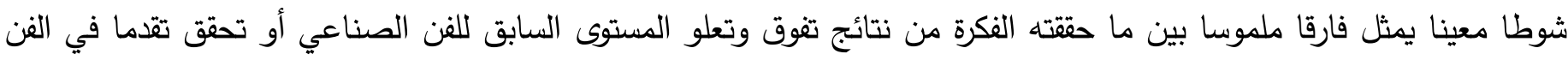

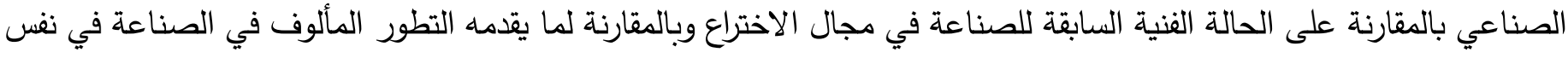
الوقت vii

إذا كان موضوع الاختراع في الطبيعة لا يمثل عقبة لتحقيق شرط الجدة فإن الأمر يختلف إذا تعلق الأمر بالخطوة الإبداعية

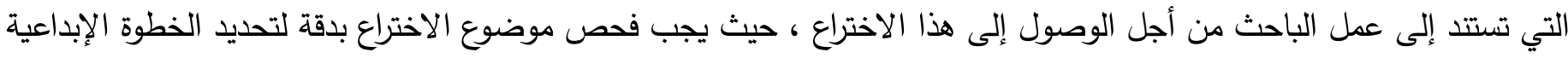

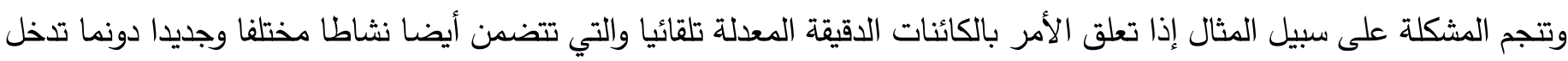

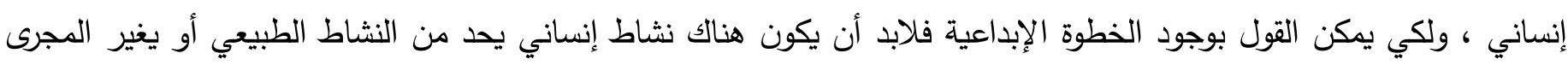

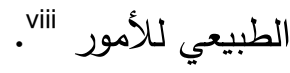
و الابتكار في اختراعات التكنولوجيا الحيوية فإنه يتم تقييمه بعد التأكد من توافر شرط الجدة ، فإن كان الاختراع جديدا في مجمله آو في بعض عناصره فإنه يتم فحص العنصر الجديد للتأكد من استيفائه لشرط النشاط الابتكاري ، فإذا كان الاختراع منتجا جديدا مثل كائن دقيق أو طريقة غير بيولوجية أو بيولوجية دقيقة فإنه يتم تحديد إذا ما كان هذا المنتج أو الطريقة قد تم بتدخل الإنسان 


\section{Proceeding of $6^{\text {th }}$ nternational Conference of Biotechnology, Environment and Engineering Sciences}

(ICBE6) 28 - 29 December 2019, Alexandria-Egypt

وذلك لاستيفاء شرط الجدة ،ثم تحديد درجة التذخل الإنساني و ذلك للتحقق من توفر شرط النثاط الابتكاري . جــــابلية الاختراع للتطييق الصناعي

لا يمكن القول أن الاكتثافات الناجمة عن علم الأحياء والهندسة الوراثية اختراعات محمية عن طريق البراءة إلا في حالة

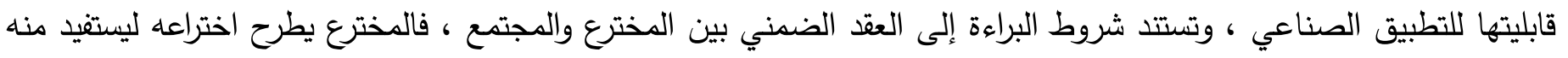

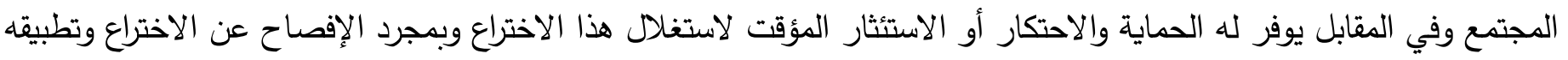

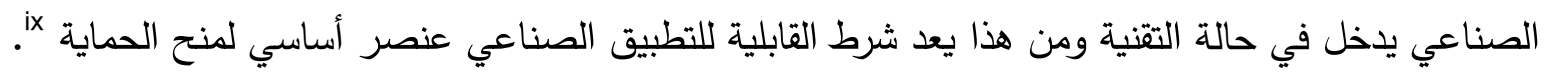

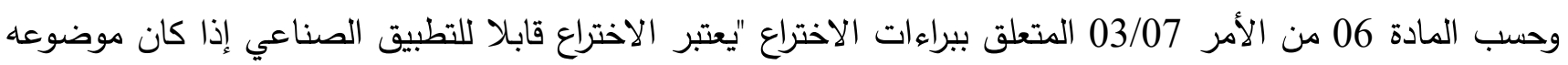

قابلا للصنع أو الاستخدام في أي نوع من الصناعة".

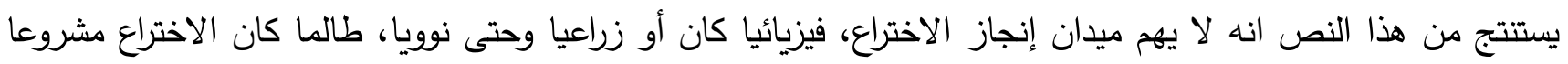

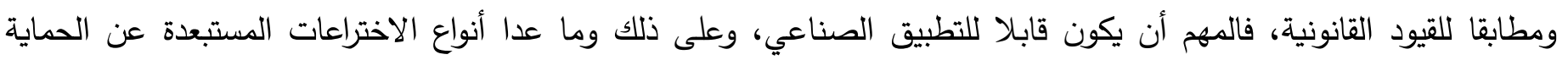

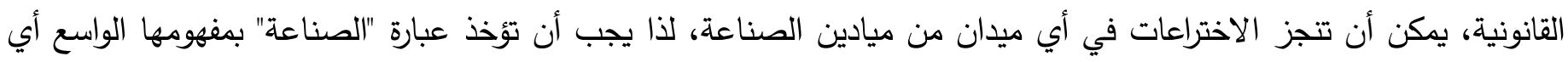

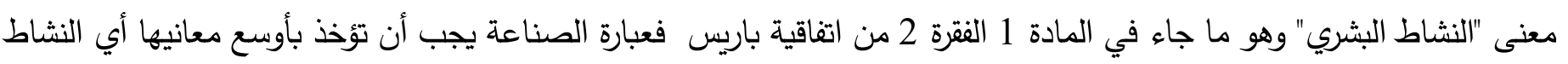

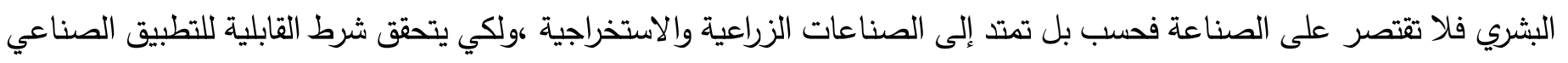

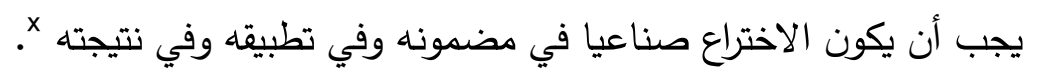

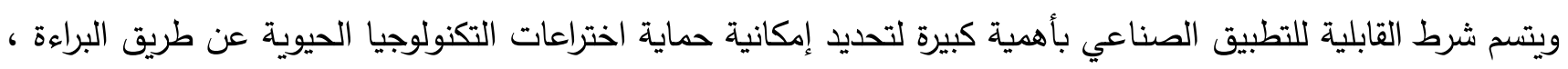

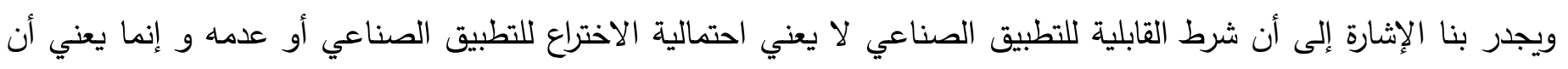

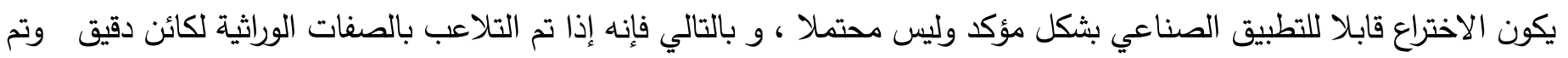

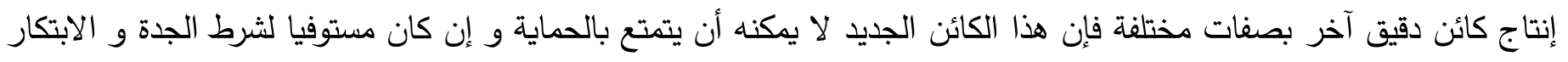

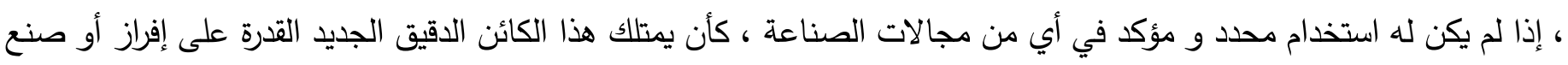

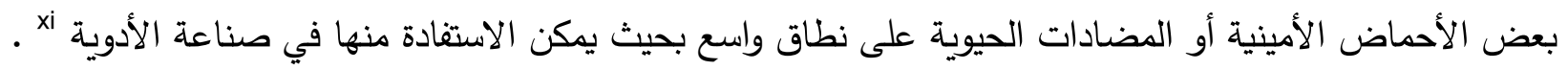

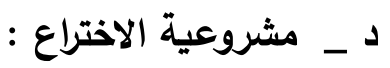

من شروط منح البراءة هو أن يكون موضوعها مشروعا في نظر القانون، وقد تقع الشرعية بتحديد القانون لغير المشروع أو الو القأ

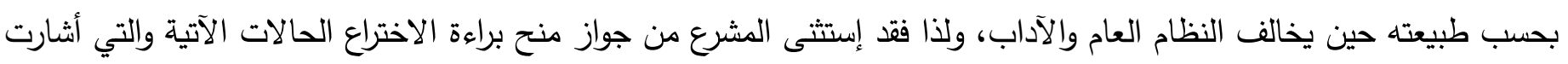

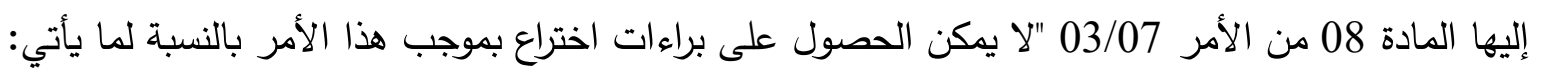

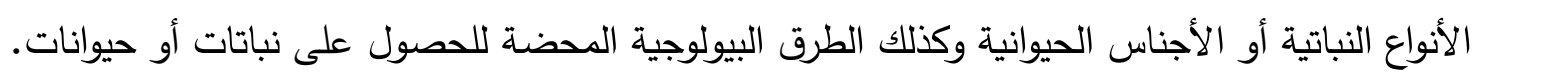

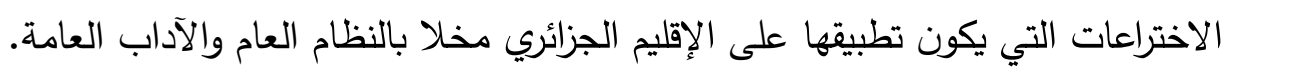

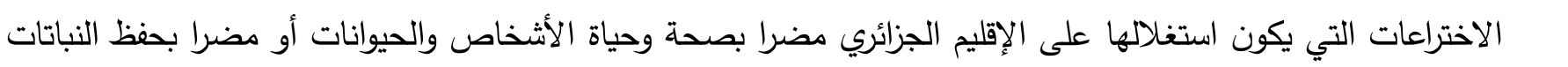
أو يثكل خطرا جسيما على حماية البيئة".

_ _ الاختراعات المتعلقة بالأصناف النباتية والأجناس الحيوانية: لم يكن الابتكار في مجال النبات محلا لأي حق في الماضي ، ولكن تغير هذا الموقف وتزايد الاهتمام بنح حماية حقوق 
الملكية الفكرية للإبداع والابتكار في مجال النبات خاصة بعد الدور الموسع للثركات الخاصة في الدول المتقدة في البحث الزراعي

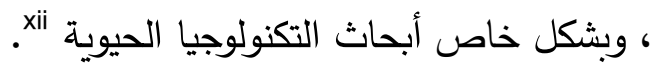
تعتبر الأصناف النباتية الجديدة احد أشكال الملكية الفكرية التي أكدت اتفاقيات الملكية الفكرية على ضرورة حمايتها وذلك

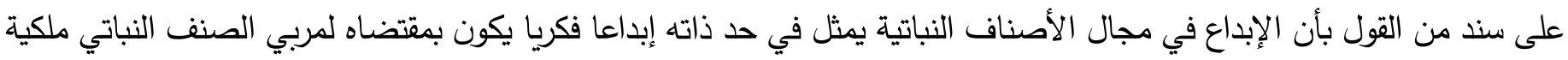

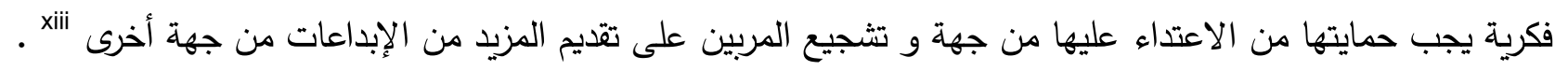

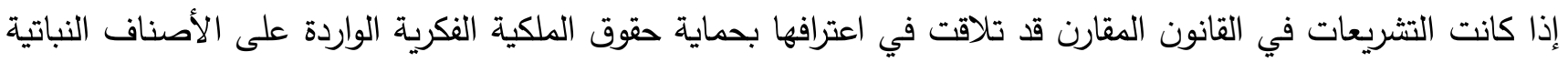

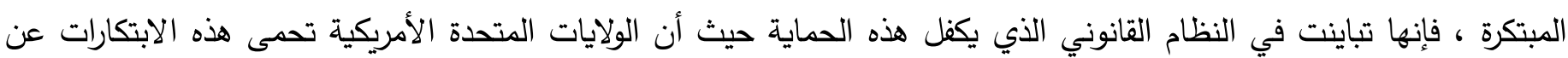

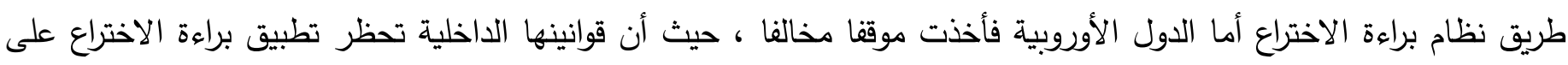

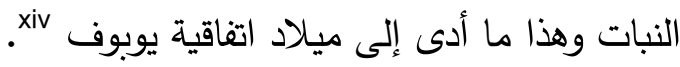

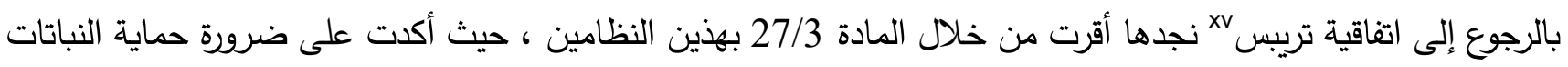

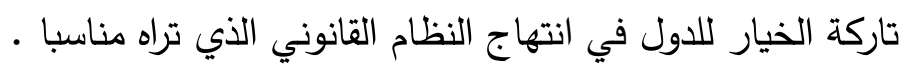
وفي هذا السياق انتهج المشرع الجزائري طبقا للقانون 05/03 المؤرخ في 6/2/2005 المتعلق بالبذور والثتائل وحماية الحيازة

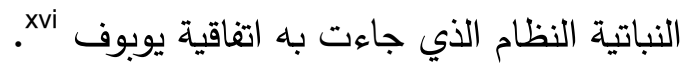

_ الاختراعات التي يكون تطبيقها على الإقليم الجزائري مخلا بالنظام العام أو الآداب العامة:

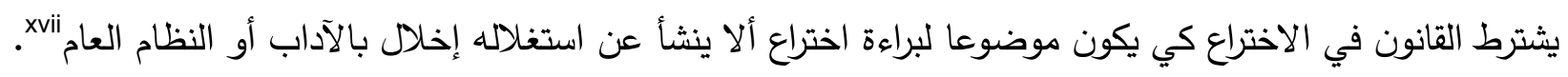

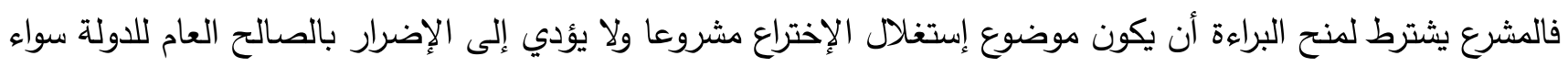

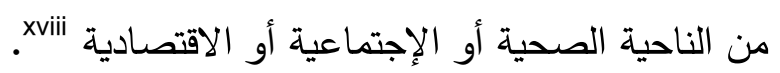
وبهذه المناسبة يثور التساؤل بالنسبة للابتكارات التي يترتب عن إستا الست غلالها استعمالا مزدوجا، كما إذا ترتب عنها مزايا

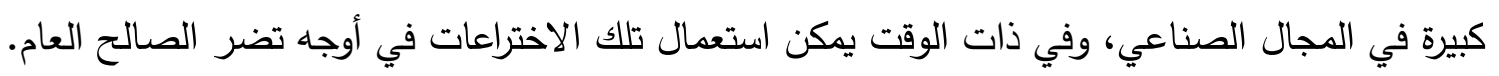

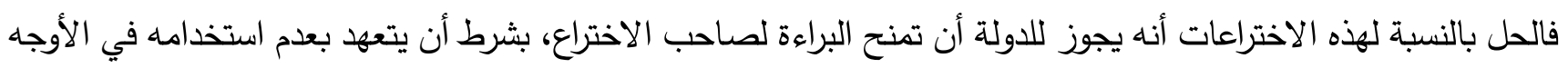

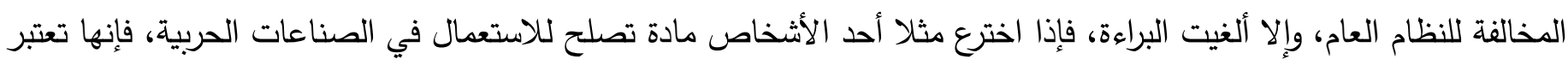

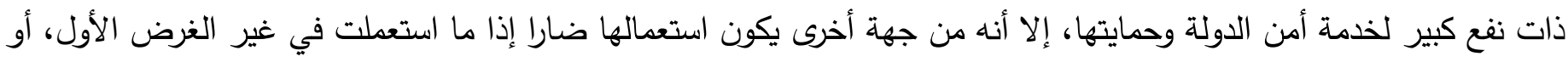

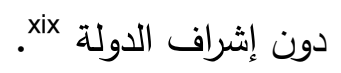

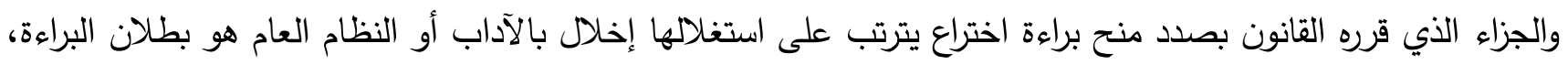

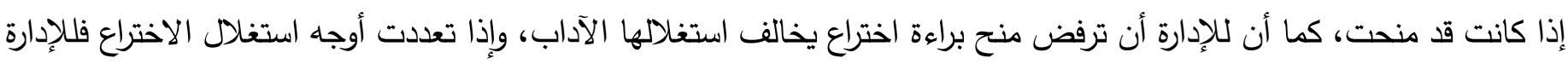

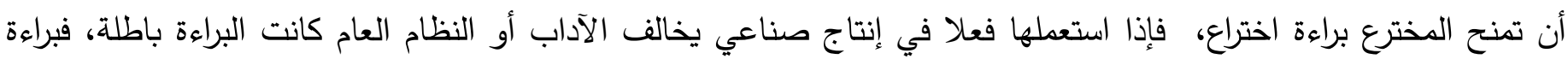

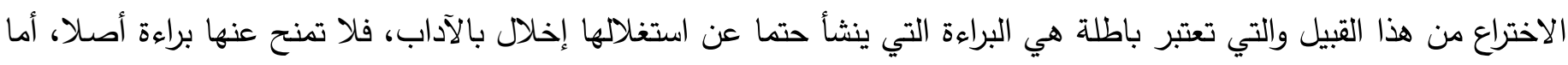

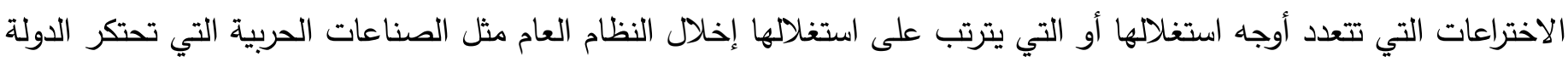

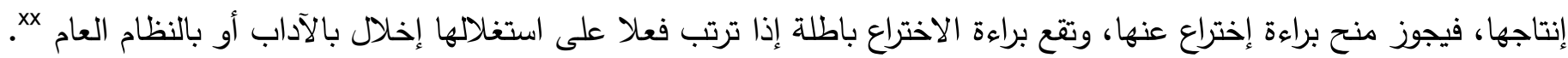

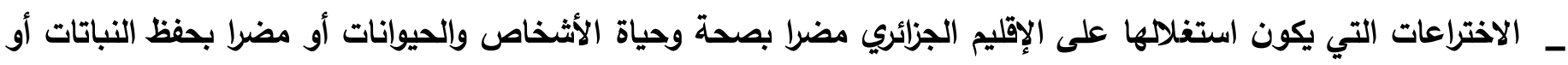




\section{يشكل خطرا جسيما على حماية البيئة:}

يتضح من النص المشار إليه هو توسع المشرع في مفهوم النظام العام وحسن الآداب، حيث ظهرت في الأزمنة القريبة

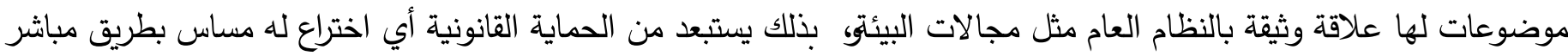

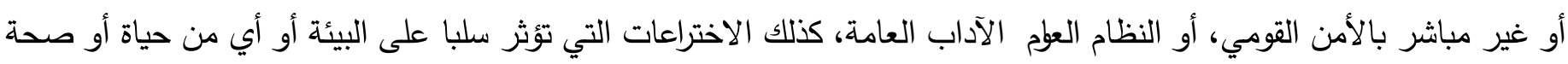
الإنسان أو الحيوان أو النبات دxi

مثل ذلك الاختراعات المتعلقة بأجزاء أو مكونات من جسم الإنسان كالخلايا والدم والبروتين البشري والهرمونات والجينات

$$
\text { وكذلك الاختراعات المتعلقة بعطليات الاستتساخ. }
$$

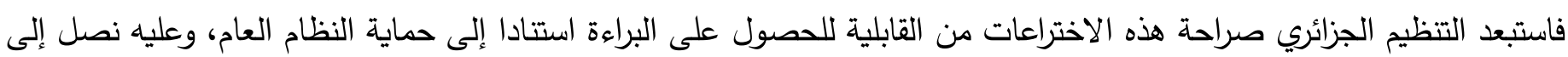

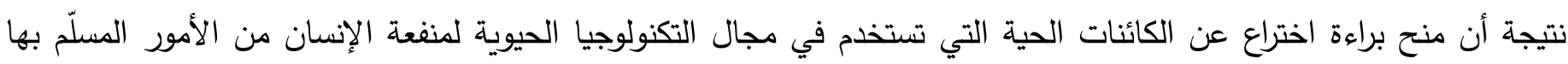
شريطة أن تتوفر فيها الثروط المفروضة قانونا لهنح براءة الاختراع.

2

إن اتفاقية تربس قد تركت الحرية الكاملة لكل تشريع داخلي ليقرر ما يثاء بالنسبة لهذا الموضوع ، حيث تتص في مادتها الأولى و في الجزء الأول تحت عنوان نصوص عامة و المبادئ الأساسية " أن الأعضاء تلتزم بتتفيذ هذه الاتفاقية ، على لئى أنه يجوز

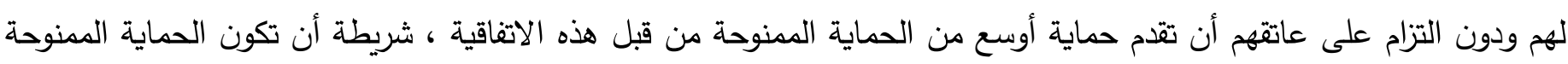

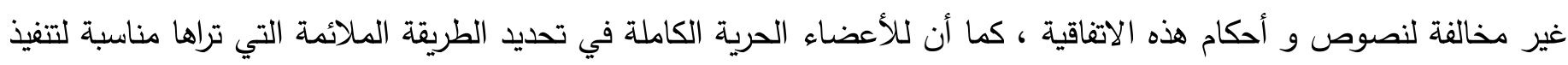

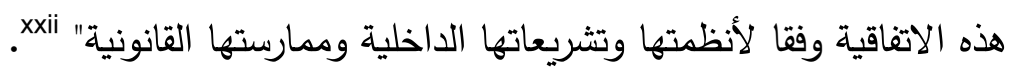

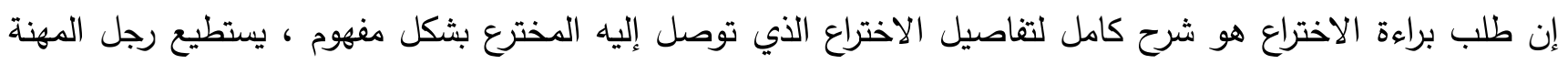

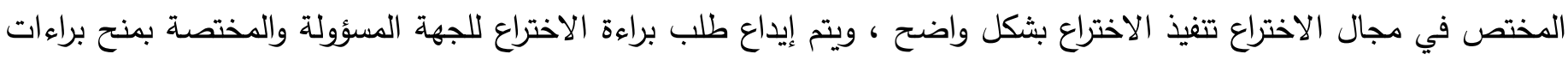

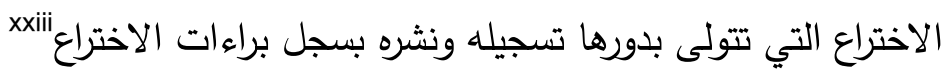

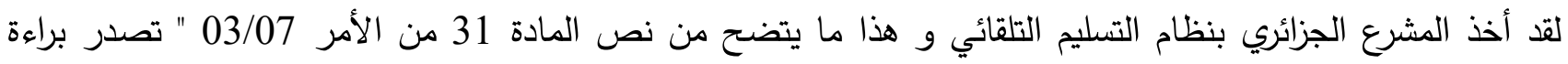

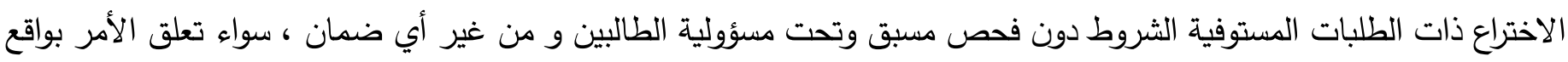

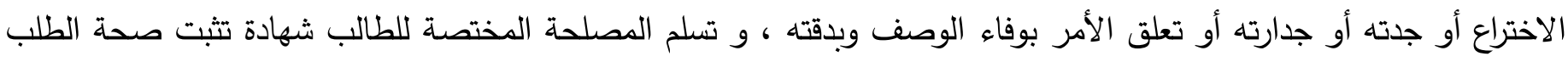

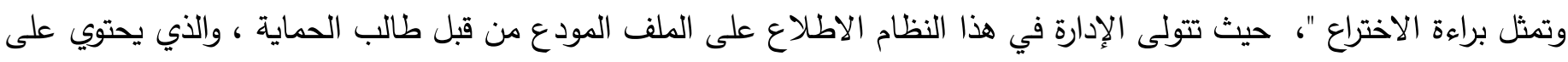

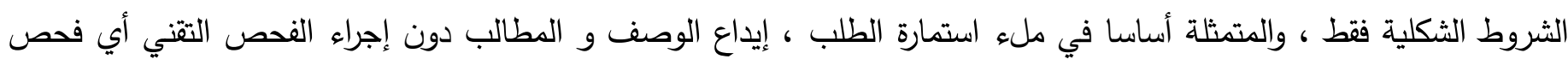

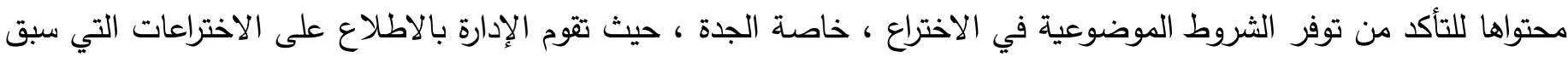

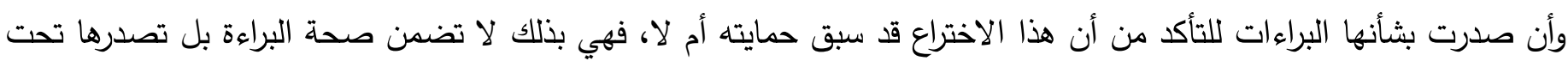

$$
\text { مسؤولية صاحبها وهذا ما أكدته المادة } 21 \text { من الأمر }
$$

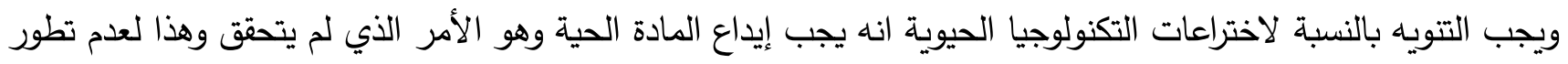

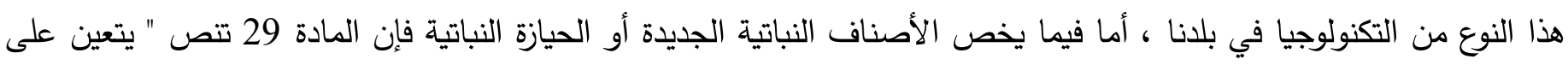
الطالب أن يقدم كل معلومة أو وثيقة أو مادة نباتية تطلبها السلطة الوطنية للفحص فيأ ..." ، وكذلك ما جاء في المادة 43/ 2 " . ... 
وبهذه الصفة يتعين عليه أن يقدم بناءا على طلب السلطة الوطنية التقنية النباتية كل المعلومات أو وثيقة و / أو مادة نباتية تراها

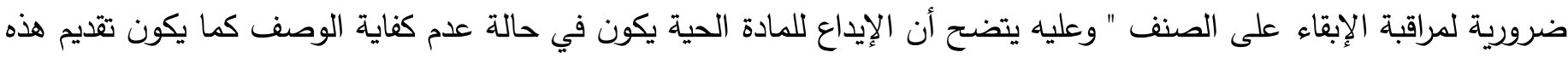

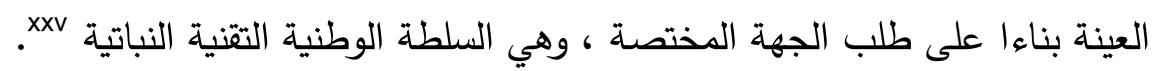

\section{ثانبا__أهمية إيراء التكنولوجيا الحيوية :}

مع بداية القرن العشرين المنصرم ، حدث تطور مذهل في علم الوراثة والأحياء الدقيقة ، وخصوصا بعد اكتياء التشاف (واطسون

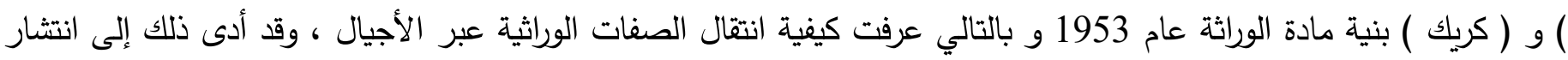

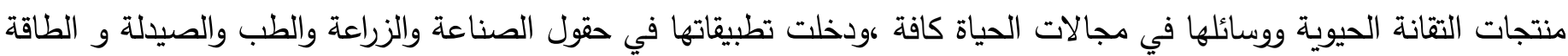
والتعدين و البيئة xxvi

لذلك أصبح للتكنولوجيا الحيوية أهمية كبيرة في جميع مجالات الحياة المرتبطة مباشرة بالإنسان مما أدى بضرورة إبرائها

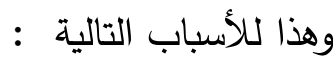

\section{1 ـ تثجيع روح الابداع والاختراع :}

تعتبر معظم الابتكارات ثمرة جهد ثمين وطويل للباحثين لم تكن لتظهر على أرض الواتل الواقع لولا ضمان تعويض ملائم لمن

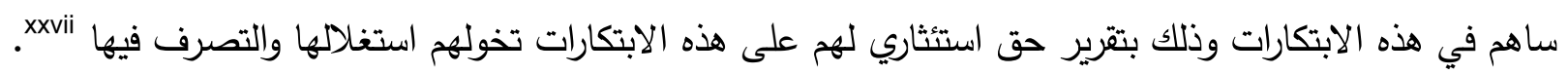

\section{2 ـ حماية المخترع :}

إن حماية المبتكر ضرورة قانونية تقتضيها الأمانة ، إذ أنه حق كسائر الحقوق يتطلب تدخل المشرع لسن تشريعات لتجسيده

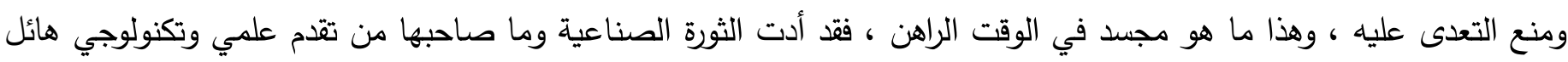

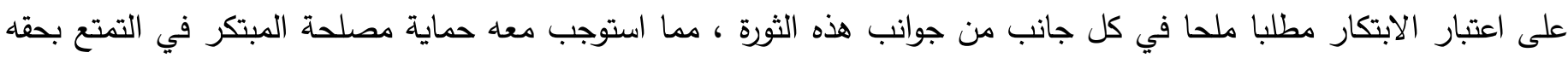

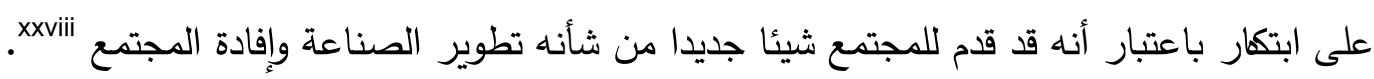

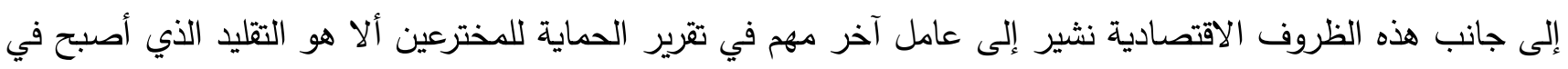

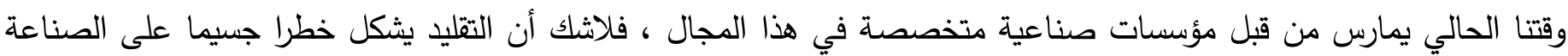

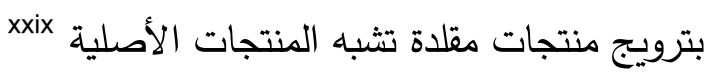

\section{3 ـ الحفاظ على الملكية الفكرية ومحاربة القرصنة الفكرية الوراثية :}

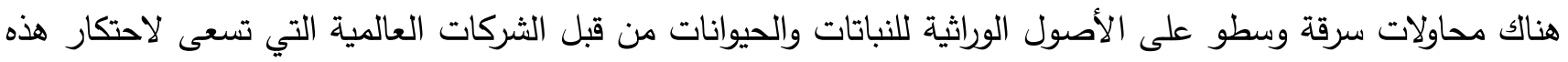

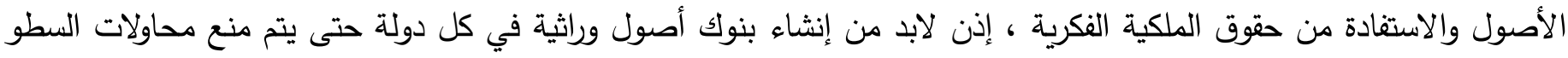

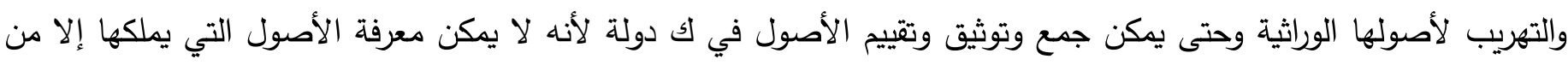

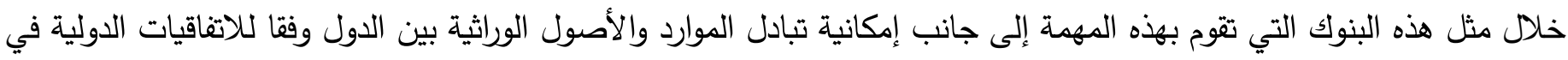

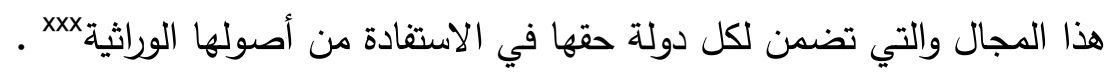
4 ـ براءة الاختراع أداة لنقل التكنولوجيا : ان الاستغلال الحكيم والعقلاني لبراءات الاختراع يؤدي إلى احداث ثورة علمية تكنولوجية ، فمن المتفق عليه في الوقت الراهن

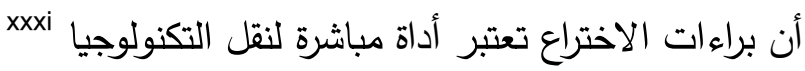




\section{: 2 - 2 معالجة الفضلات}

تلعب التقانة الحيوية دورا هاما في معالجة الفضلات ، مثل معالجة مياه الصرف الصحي والتخلص من الفضلات الصناعية والزراعية لاستهلاكها في إنتاج الطاقة أو تحويلها إلى مركبات قابلة للتخمر بواسطة الكائنات الحية الدقيقة ثم إلى بروتينات مفيدة xxxii

$$
6
$$

يهدف نظام براءات الاختراع إلى تحقيق أهداف التتمية الثاملة المتمثلة في استغلال الدولة لمواردها وثرواتها الطبيعية ،

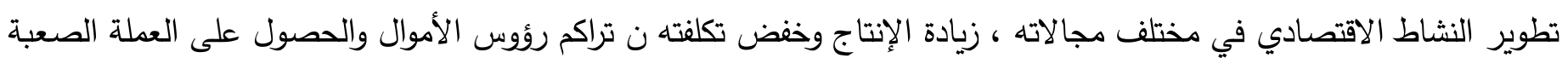

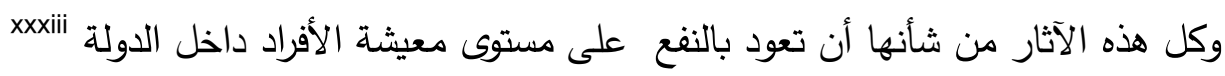

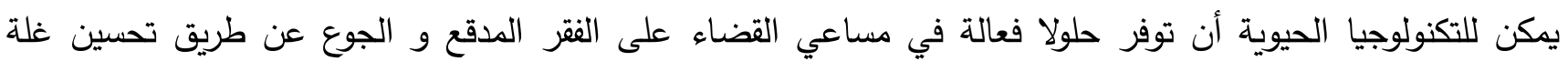
المحاصيل بالإضافة إلى تخفيض معدل وفيات الأطفال وتحسين الصحة النفاسية عن طريق رفع القيمة التغذوية للأغذية . 7 التكنولوجيا الحيوية شأنها شأن أي علم آخر تتوقف درجة أمانها على طبيعة الاستخدام ، فكما يمكن استخدامها بثكل مفيد

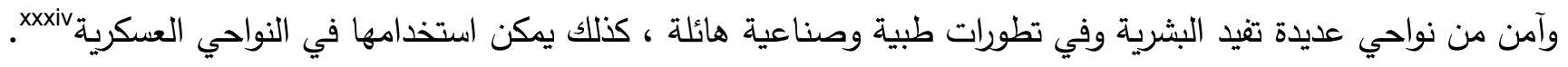

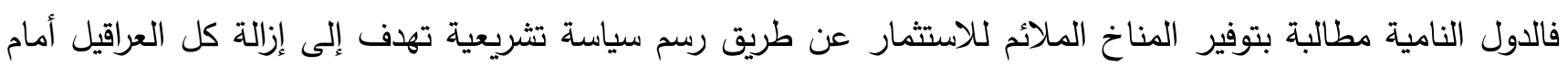

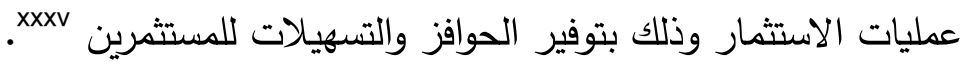
8 ان من بين الحوافز والتسهيلات التي يجب على الدولة المضيفة توفرها لجلب الاستثمارات الاجنبية وضع حمية جدية وفعالة الإنية

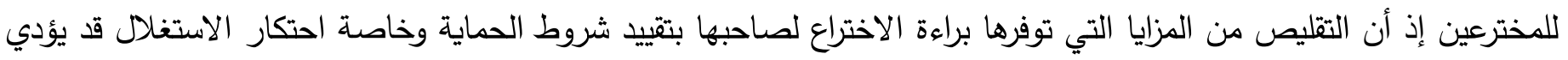

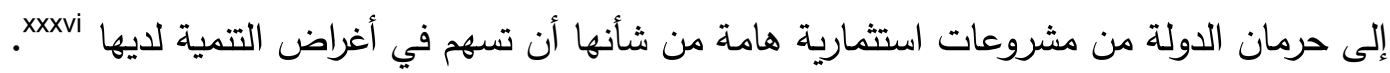

\section{المحور الثاني : (1) \\ حقوق صاحب براءة الاختراع}

تخول براءة الاختراع صاحبها حقا مؤقتا في احتكار استغلال الاختراع، وحق التصرف في الباعة البراع البراءة بالتتازل عنها أو الترخيص

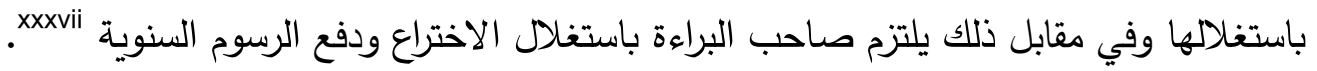
والاستغلال ليس حقا لصاحب البراءة فحس، وإنما هو واجب عليه أيضا، بحيث إذا أهمل أو أو تراخى في شأنه، جاز إجباره على الترخيص للغير بالقيام بالاستغلال xxxviii. أولا :حقوق صاحب براءة الاختراع 1 عقد الترخيص الاختياري من العقود الثائع استعمالها لاستغلال براءات الاختراع نظرا لفائدته للمخترع الذي قد لا تتوافر لديه

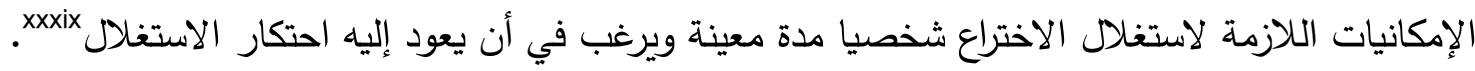


الترخيص الاختياري هو العقد الذي بمقتضاه يخول مالك البراءة شخص آخر استغلال الاختراع في مدة معينة لقاء أجر معلوم

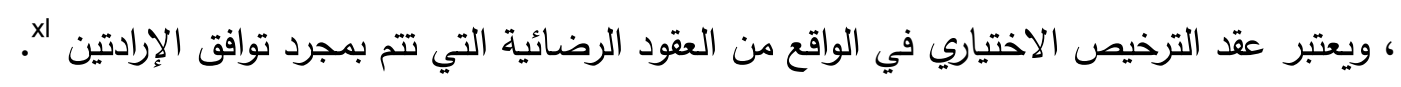
فالمقصود باستغلال الاختراع هو الإفادة منه ماليا بالطرق والوسائل التي يختارها صاحب البراءة ويراها صالحة للاستغلال

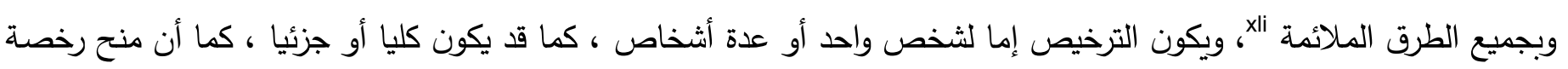

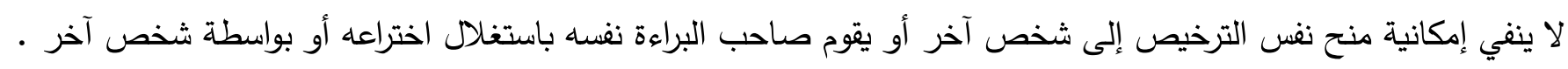
2

لقد نصت المادة 11 من الأمر 03/07 فقرة أخيرة "لصاحب البراءة الحق كذلك في التتازل عنها أو تحويلها عن طريق الإرث وإبرام عقود تراخيص".

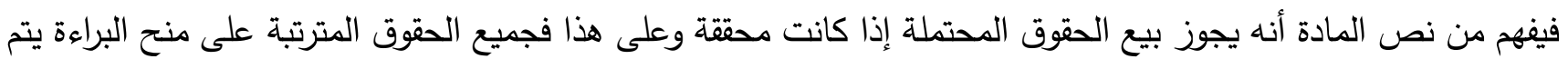

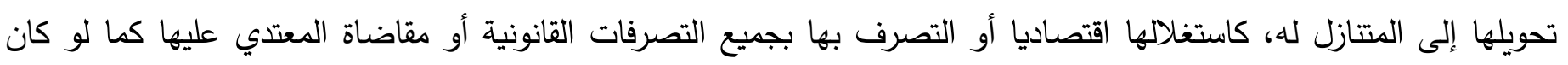
صاحبها الأصلي. وقد يكون التنازل عن البراءة جزئيا بموجب اتفاق بينهما يحدد الجزء الذي تتازل صاحب البراءة عنه، ويختلف هذا التتازل باختلاف الاتفاق. كالتازل عن بعض الحقوق المترتبة عليها مثل التتازل عن حق الإنتاج فقط، أو التتازل عن حق البيع فقط، أو التنازل عن حق الاستغلال مدة معينة تعود البراءة بعدها إلى المتنازل.

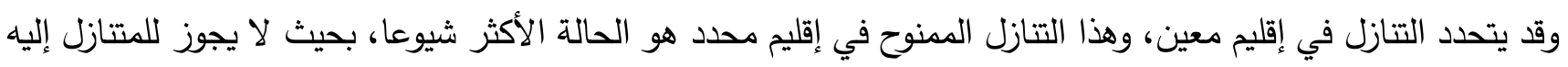

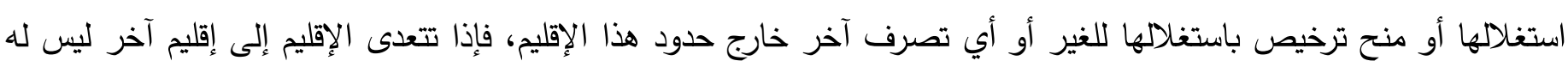

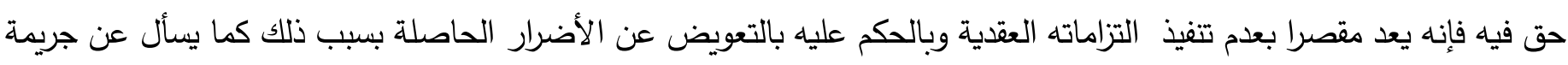

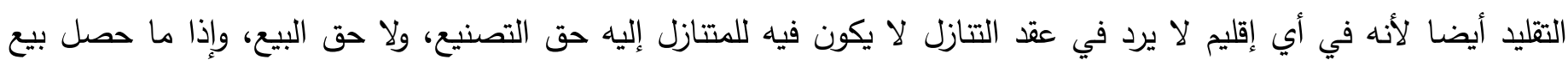

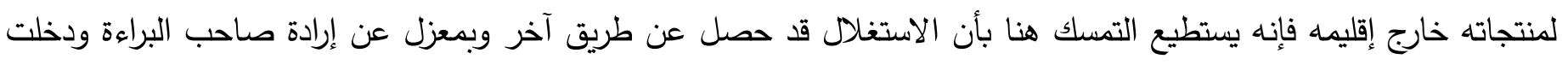

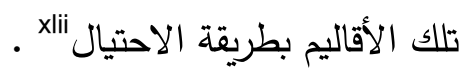

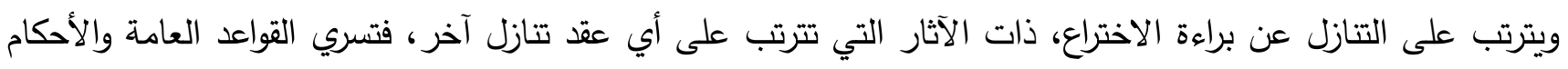

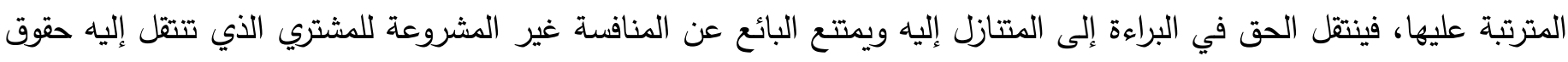
البائع في التصرف والاستغلال. ويشمل التتازل عن البراءة الحقوق المادية دون المعنوية، فلا يجوز للمشتري أن ينسب الاختراع إليه، فإذا فعل ذلك جاز

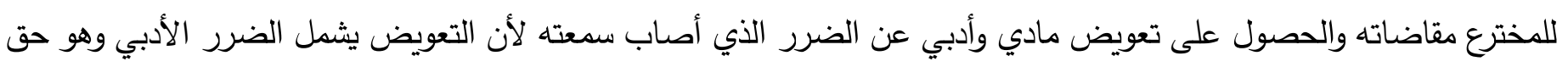
السمعة الذي لا يجوز التنازل عنه.

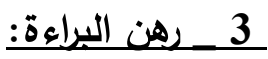
يعد رهن براءة الاختراع من آثار حق التصرف في الاختراع، متى ثبت للمخترع حقه في الحصول على براءة الاختراع حسب الأصول،

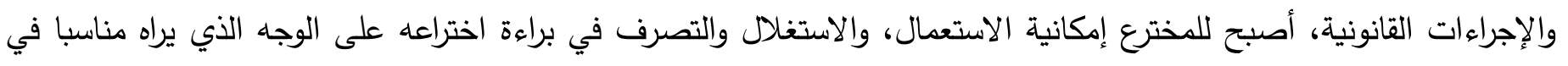


إطار أحكام التشريع المعمول به، وفي هذا الثأن يجوز رهن البراءة لضمان دين على صاحبها، فتطبق والحالة هذه أحكام القانون

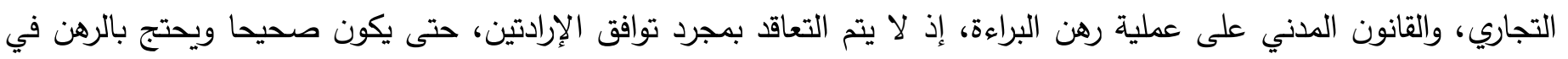

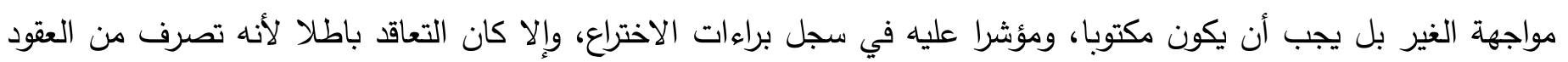

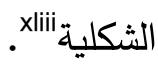

ويجب إثبات رهن البراءة كتابيا وتسجيلها في سجل البراءات طبقا للمادة 36/2 من الأمر 03/07 والتي تقضي "تثترط

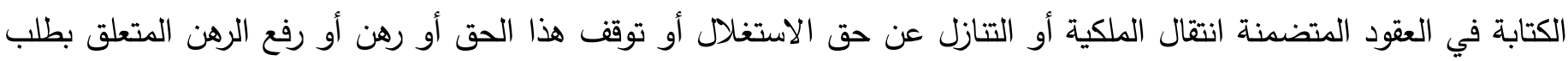

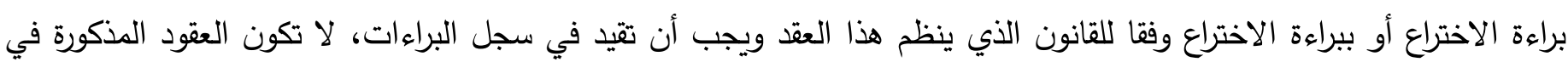
الفقرة أعلاه، نافذة في مواجهة الغير إلا بعد تسجيلها". ولما كانت البراءة من المنقولات وجب إتباع أحكام رهن المنقول ومن ثم يشترط لنفاذ رهن البراءة في حق الغير التهاء أن تسلم

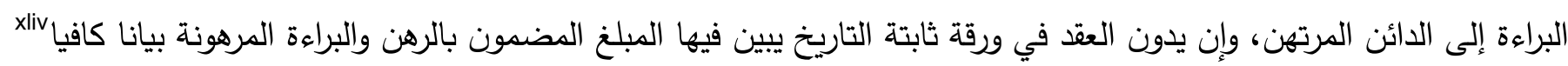

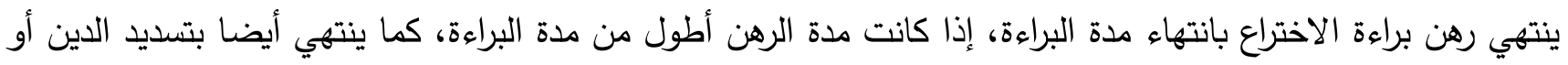

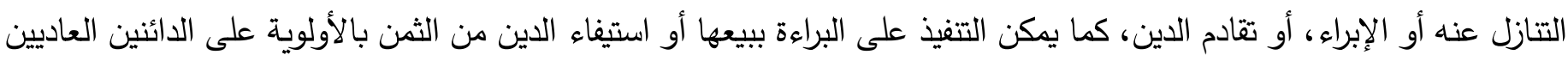

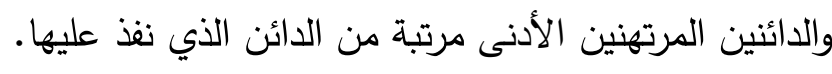
4 بناء على القواعد العامة للشركات، يجوز تقديم براءة الاختراع للمساهمة في شركة إما بصفة منفردة أو أثناء تقديم محل تجاري

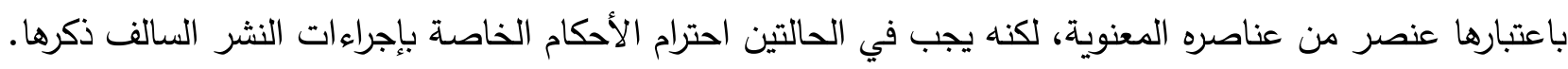

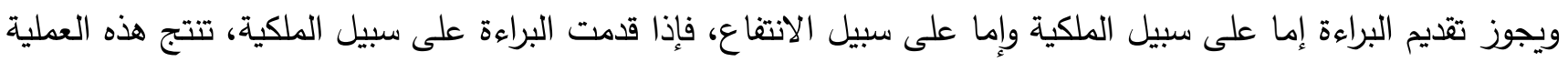

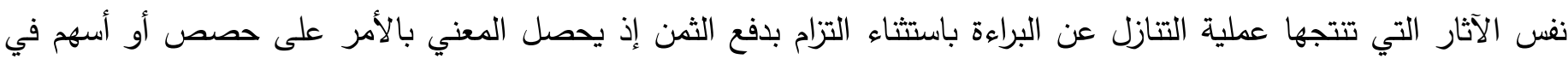

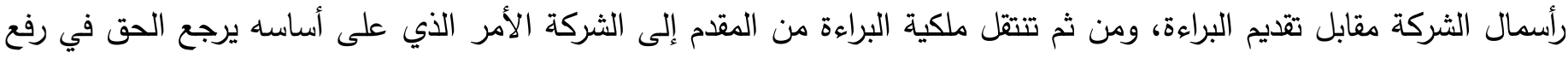
دعوى التقليد إلى الثركة ونظرا لتطبيق أحكام عقد البيع، فإن الثريك المقدم يفقد كافة الحقوق التي كان يملكها على المال الدقدم

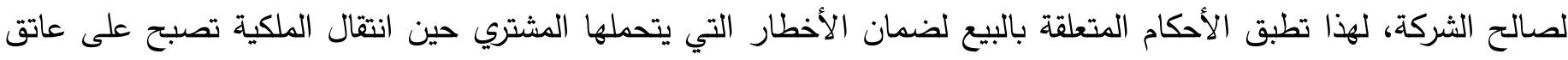

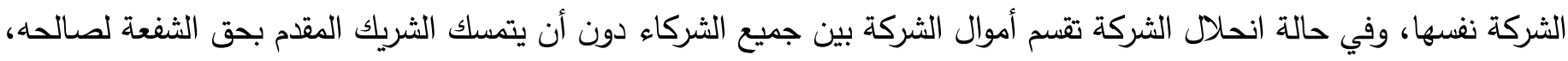

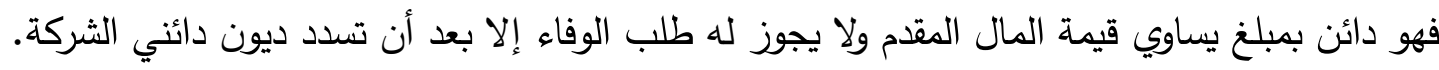

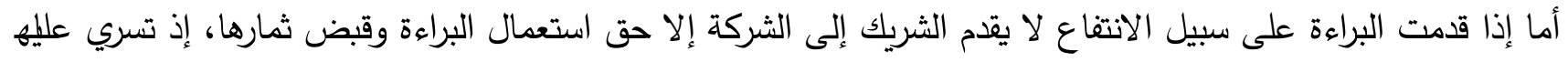

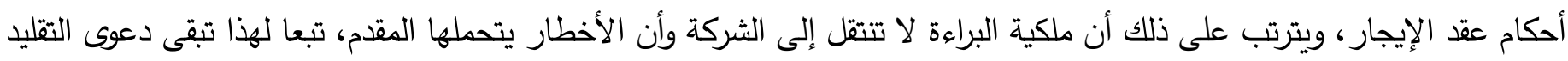

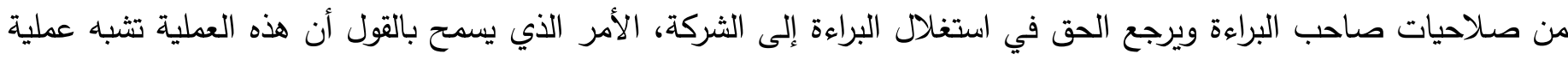

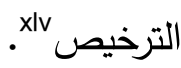

\section{ثانيا : التزامات صاحب براءة الاختراع:}

في مقابل الحقوق التي تخولها البراءة لمالكها من استئثار لاستغلالها والتتازل عنها وإعطاءه ترخيصا للغير باستغلالها، فهناك التزامات تقع على عاتق مستغل هذه البراءة سواء كانت شخص طبيعي أو معنوي وهذا نظرا للوظيفة الاجتماعية التي تؤديها ملكية 
تقضي المادة 09 من الأمر 03/07 "مدة البراءة هي عشرون (20) سنة ابتداء من تاريخ إيداع الطلب مع مراعاة دفع رسوم

التسجيل ورسوم الإبقاء على سريان المفعول وفقا للتشريع المعدول به".

يتضح من خلال المادة 09 أن المشرع أقر نوعين من الرسوم أو الحقوق التي يجب دفعهاء وهي وهي:

1- 1 - رسوم تدفع عند التسجيل.

2- رسوم الاحتفاظ بصلاحية البراءة أو ما يطلق عليه بالرسم السنوي.

لقد فرض المشرع على صاحب البراءة رسما ماليا محددا يجب عليه أداءه عند إيداع طلب الحصول على براءة اختراعه وأيضا عند طلب تجديدها وجدير بالإشارة أن هذه الرسوم لا ترد إلى دافعها فيما لو رفض طلبه لأي سبب من الأسباب.

فإذا منحت البراءة يلتزم صاحبها بدفع رسم يستحق سنويا طوال مدة البراءة ولحين انتهائها.

إن إرادة المشرع كانت ربط استمرار البراءة بدفع الرسوم التظظيمية، حيث نص على هذا الالتزام في المادة التي تحدد مدة الحماية القانونية ولذا قرر أن ملكية البراءة تسقط في حالة امتتاع صاحبها عن دفع الرسوم التنظيمية السنوية في المهلة المحددة قانونا، غير أن لصاحب البراءة مهلة ستة (06) أشهر ابتداء من تاريخ مرور سنة على الإيداع لدفعها، أي يستفيد من مهلة إضافية للقيام بدفع الرسوم، لكنه ملزم بدفع رسم إضافي عن التأخير

2 ـ التزام مالك البراءة باستغلال الاختراع

يعتبر دنح المخترع حق استغلال براءة الاختراع بمثابة عقد اجتماعي يقابله أن يلتزم المخترع باستغلال براءته لإفادة المجتمع xlvii

وهذا الالتزام يعني أن الحماية تمنح لأهداف نفعية تخص الجماعة بأسرها ، وتتمثل هذه الأهداف في تثجيع المخترعين على

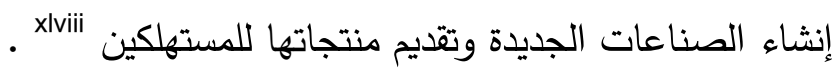
إن العبرة في واجب استغلال الاختراع تشجيع الجهود العلمية لتحقيق التقدم الصناعي ويظهر حق احتكار استغلال الاختراع كالحافز اللازم للتقدم الصناعي، لذا ينبغي ألا يعرقل هذا التطور، فإذا لم يستخل فعلا فقدت الحماية سببها، لذلك تقضي أغلبية التشريعات على حق بوجوب استغلال الاختراع خلال فترة معينة وإلا تعرض صاحبه للترخيص الإجباري. والجدير بالذكر أنه لا يمكن للدول التي صادقت على اتفاقية إتحاد باريس اللجوء إلى إسقاط البراءة كجزاء أشد قبل انتهاء مهلة سنتين من تاريخ منح الترخيص الإجباري الأول لأنه لا يجوز النص على سقوط البراءة إلا إذا كان منح الترخيص الإجباري غير كاف لتدارك التعسف الناتج من مباشرة الحق الإستئثاري الممنوح لصاحب البراءة، وعلى كل لا جدوى في منح براءة للمخترع قصد حماية اختراعه إذا لم يقم باستغلاله xlix.

\section{الخاتمة}

إن التكنولوجيا الحيوية هي تطبيق المعلومات المتعلقة بالمنظومات الحية بهدف استعمال هذه المنظومات او مكوناتها في الأغراض الصناعية ، أي أنها تكنولوجيا قائمة على علم الأحياء خصوصا عند استخدامها في الزراعة وعلم الغذاء و الطب ، فهي تتعامل مع الكائنات الحية على مستوى الخلية وتحت الخلية من أجل تحقيق أقصى استفادة منها صناعيا وزراعيا واقتصاديا وذلك 
عن طريق تحسين خواصها وصفاتها الوراثية لأجل الاستفادة منها.

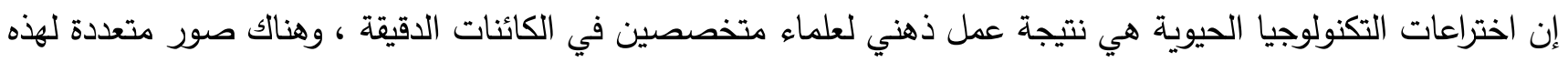

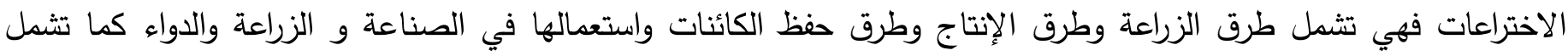

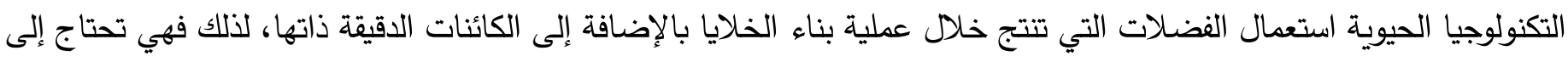

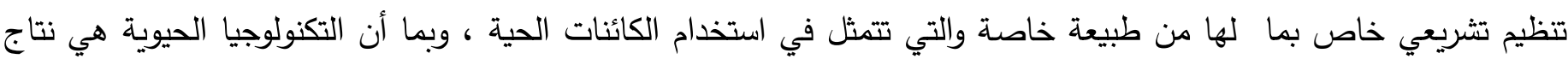
استخدام الكائنات الحية للوصول إلى منتجات جديدة فإن أبرز صور حمايتها هو براءة الاختراع •

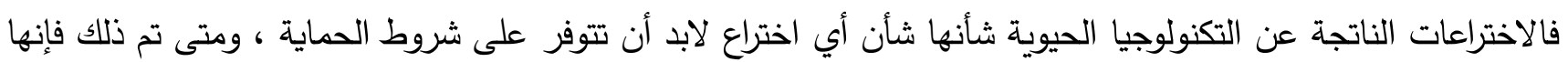
ترتب حقوق والتزامات على عاتق المخترع صاحب البراءة . إن اختراعات التكنولوجيا الحيوية تتصف بخصوصية كبيرة ذلك ان اختراعات التقانة الحيوية تسيطر عليها قوانين الطبيعة نظرا لكون محلها مادة حية وليست جامدة وايا كان الامر فلابد من توافر شروط الحماية لهنح البراءة لهذه الاختراعات الحيوية.

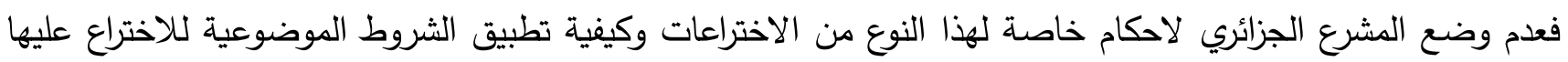

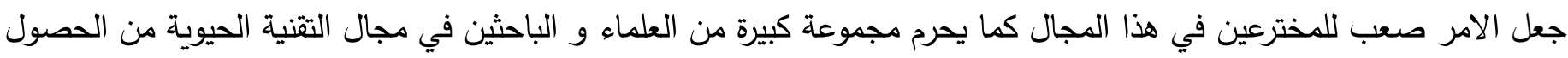

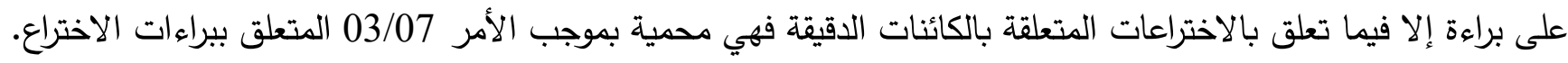

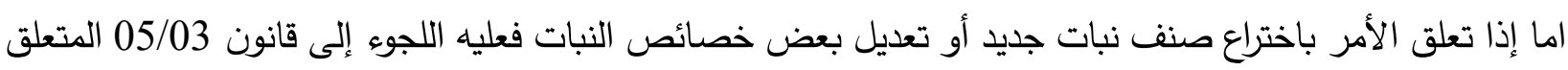
بالبذور و الثتائل و حماية الحيازة النباتية، كون المشرع من خلال الأمر ب3/07 كان الأن واضحا بحرمان الأصناف النباتية و الحيوانية من الحماية القانونية كاختراعات.

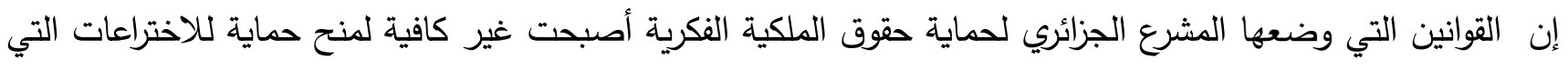

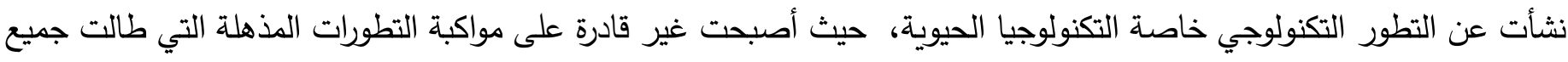

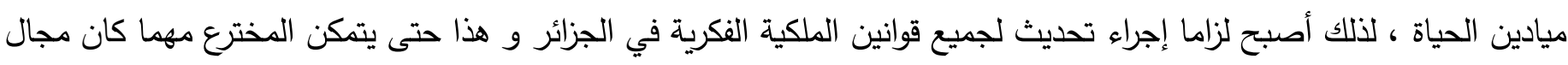
بحثه ان يستظل بحماية قانونية فعالة

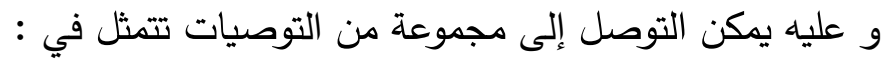

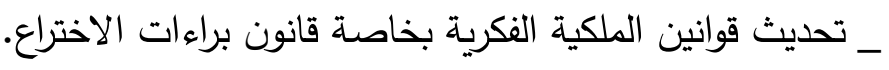

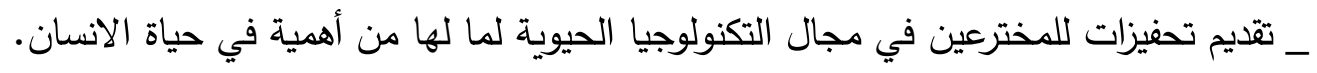

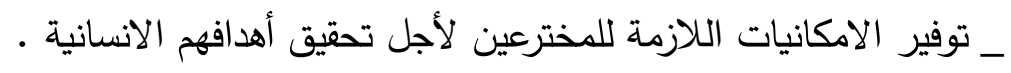

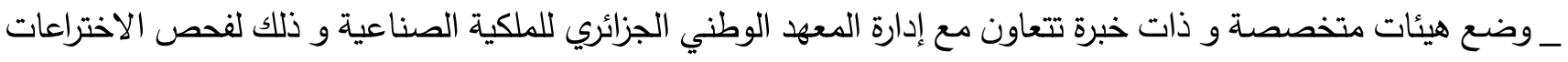
المتعلقة بالتكنولوجيا الحيوية. _ تحفيز الأنثطة الابتكارية و تثجيعها بهدف تعزيز حقوق الملكية الفكرية .

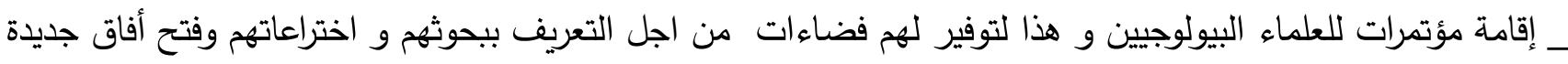




\title{
The patentability of biotechnology inventions
}

\author{
Benayad Djalila \\ Faculty of Law and Political Science, University of Mhamed Bougherra ,Boumerdes, Algeria \\ ania-rose14@hotmail.fr
}

Summary:

Biotechnology is a feature of contemporary life as it is the fourth scientific revolution of the twentieth century after the revolution of the destruction of the atom, space and computer and that its applications are not limited to a specific area but used in all areas of life.

Biotechnology is an application of information about living systems with a view to using these systems or their components for industrial purposes, they are biology -based technology especially when used in agriculture, food science and medicine.

Agricultural and economical by improving their genetic characteristics.

With the use of biotechnology, new drugs, modified plants, organic and natural substances, and development in marine organisms have emerged . from this invention, this is why we highlight in this paper the specificity of biotechnology inventions as they meet the objective requirement of patenting.

م _ محمد احمد عبد العال محمود ، الحماية القانونية للكائنات الدقيقة في القانون المصري وفي القانون الفرنسي والاتفاقيات الدولية

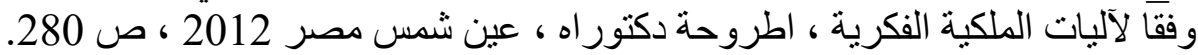

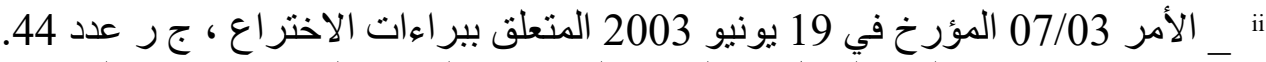

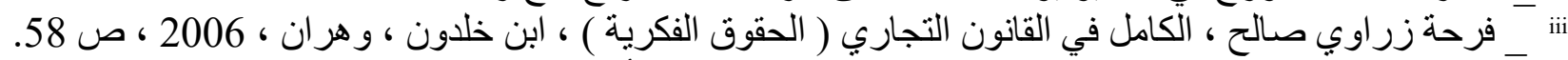

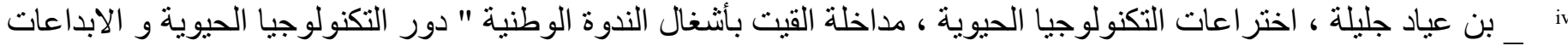

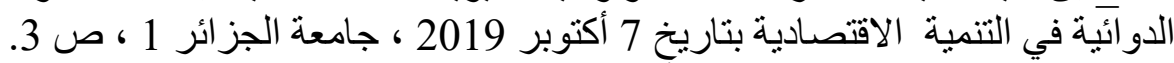

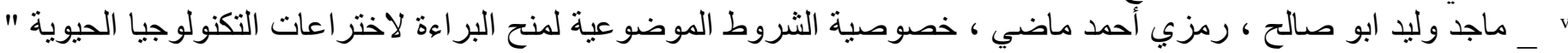

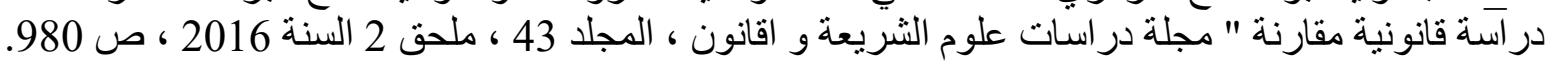

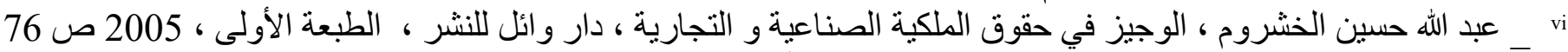

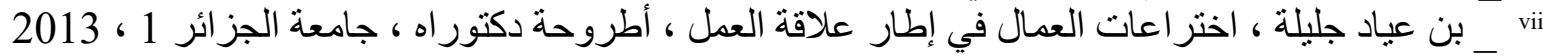

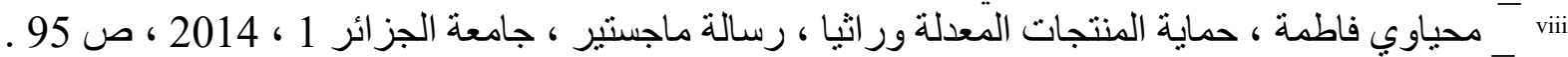

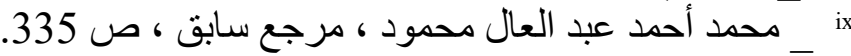

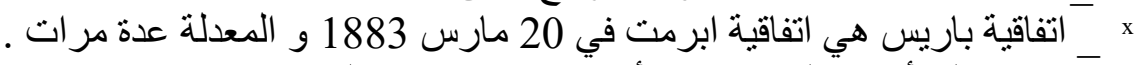

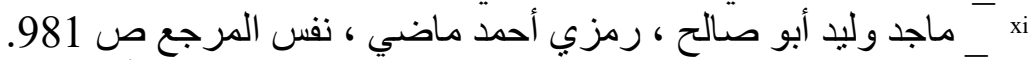

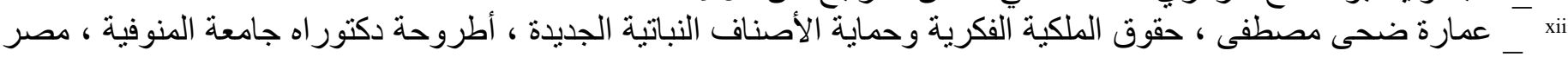
11 صواز 11011 ، 2010

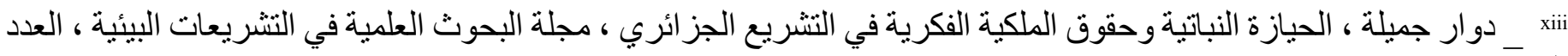

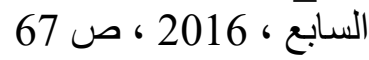

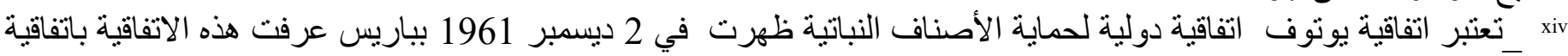

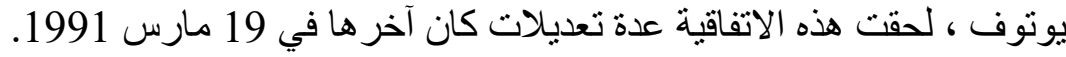

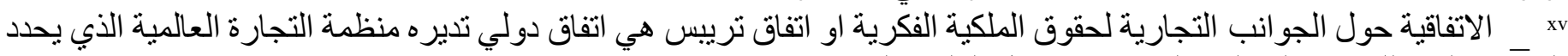

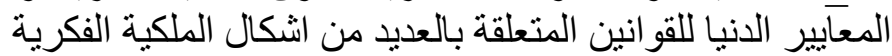

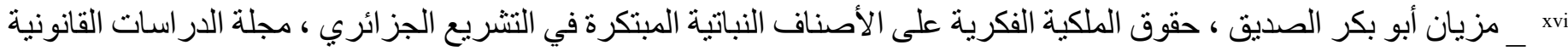

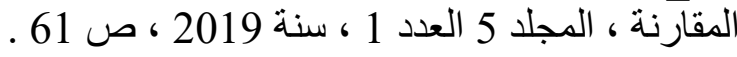
_ _ محمد حسني عباس ، التشريع الصناعي ، دار النهضة العربية ، القاهرة ، 1967 ، 76 ، 76 
القئ _ سميحة القليوبي ، النظام القانوني للاختراعات في جمهورية مصر العربية ، مجلة القانون و الاقتصاد للبحث في الثؤون

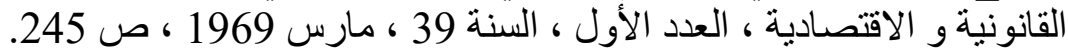

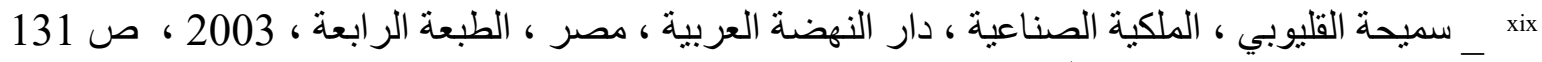

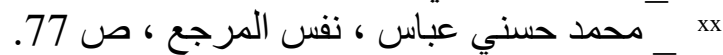

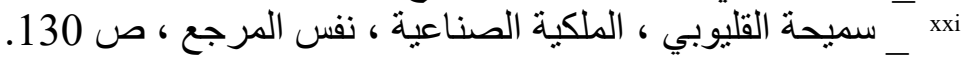
agreement between the world intellectual property organization and the world trade organization (1995), part 1, _xii Article 1/1.page 15.

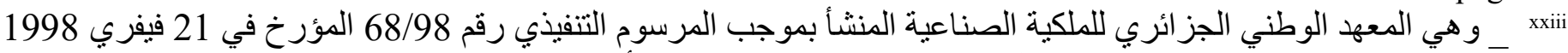

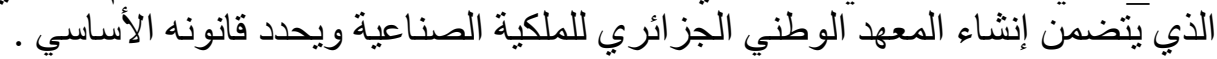

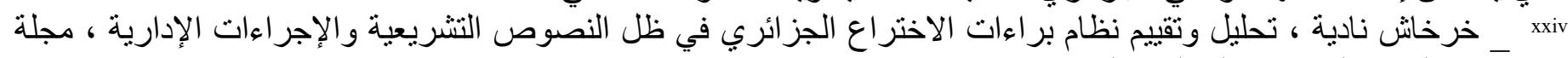

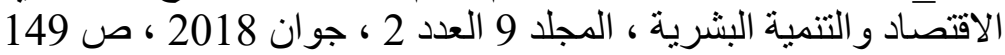

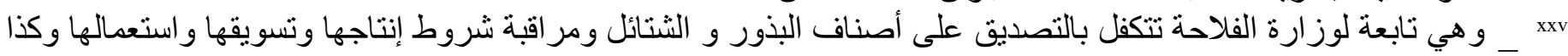
حمايةً الحياز ات النباتية و هذا حسب المة المادة 4 من القانون 03/05 المتعلق بالبذور و الثتائل و حماية الحيازة النباتية المؤرخ في 6

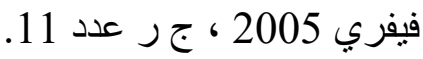

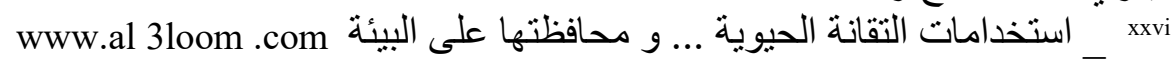
,EDIK , Oran , 2003 ,p 42. Cherchour mustapha , propriété industrielle , première édition _ ${ }^{\text {xxvii }}$ xxviii xxix

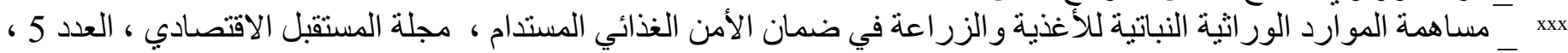
ص ص $22 \overline{7}$ xxxi _ _ هذا ما أكده تقرير الامين العام للامم المتحدة سنة 1964 " دور نظام البراءات في نقل المعارف الفنية للدول النامية " المقدم

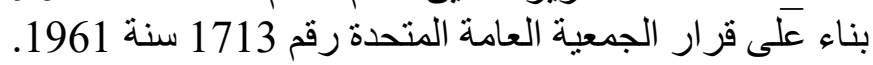

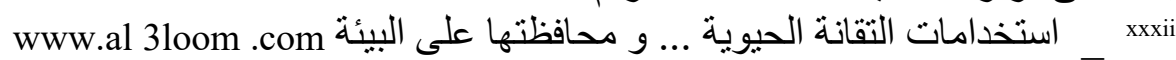

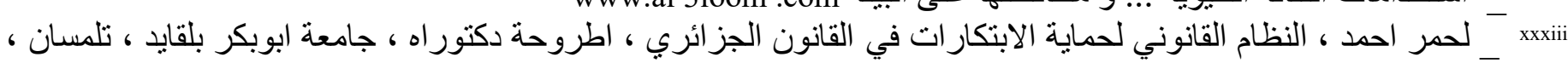

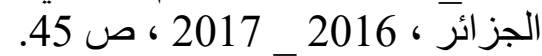
www.easyunime.com دليلك النشامل عن التكنولوجيا الحيوية _xxiv

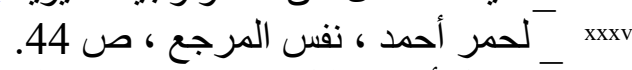
الاولي _ جxxi

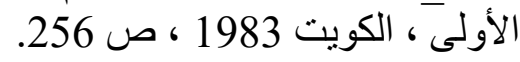

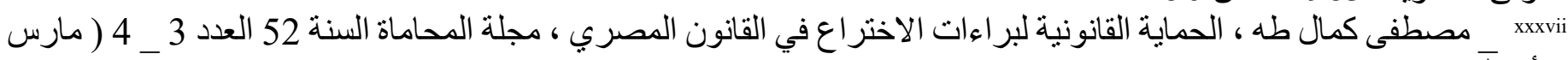

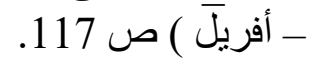
xxxviii xxxix

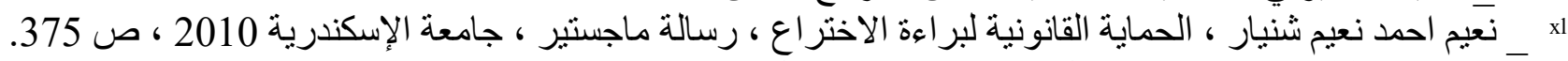
xli

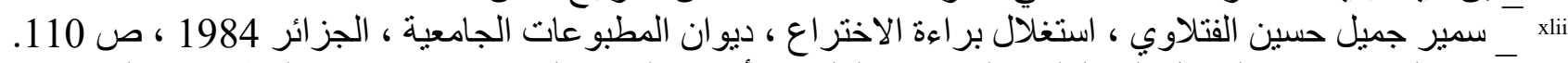

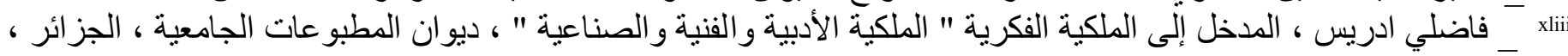

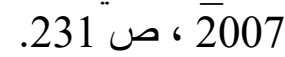

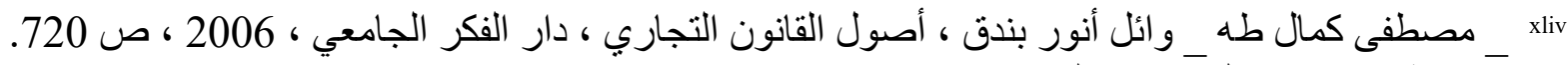

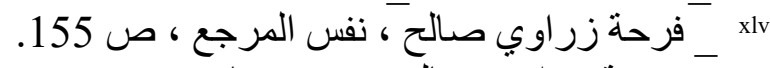

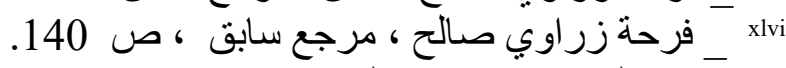

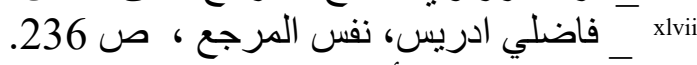

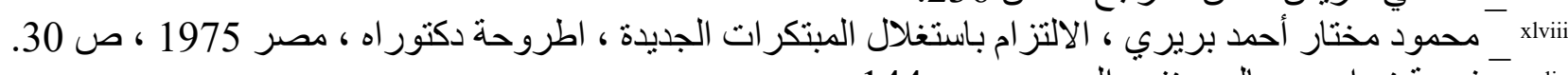


قائمة المصادر والمراجيع:

أولا : قائمة المصادر :

القوانين

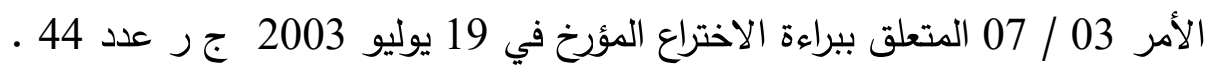

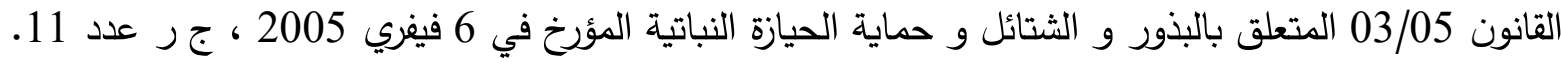

الاتفاقيات :

ـ اتفاقية باريس المبرمة في 20 مارس 1883 و المعدلة عدة مرات .

ـ اتفاقية يوتوف اتفاقية دولية لحماية الأصناف النباتية ظهرت في 2 ديسمبر 1961 بباريس ، المعدلة عدة مرات آخرها في 19 مارس 1991.

agreement between the world intellectual property organization and the world trade organization (1995) _

ثانيا : قائمة المراجع :

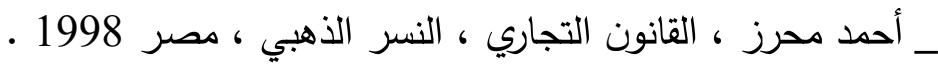
ـ جلال أحمد خليل ، النظام القانوني لحماية الاختراعات ونقل التكنولوجيا إلى الدول النامية ، منشورات ذات السلاسل ، الطبعة الأولى ، الكويت 1983.

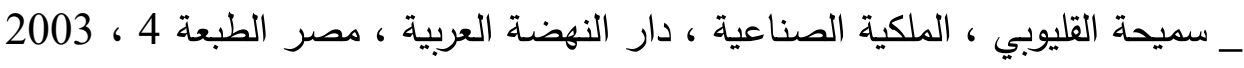
ـ سمير جميل حسين الفتلاوي ، استغلال براءات الاختراع ، ديوان المطبوعات الجزائرية ،الجزائر 1984.

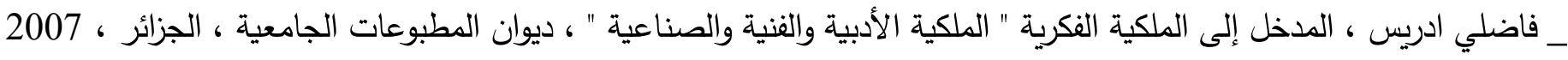

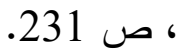

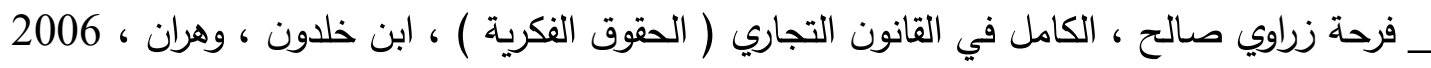

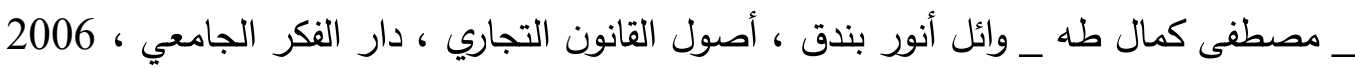

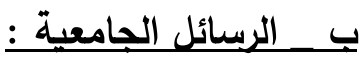
ماجستير

ـ العربي حربوش ، التقنيات الطبية وقيمتها الأخلاقية في فلسفة فرانسواداغوني ، رسالة ماجستير ، جامعة منتوري قسنطينة، الجزائر 2008 ،

ـ العايب جمال ، التتوع البيولوجي كبعد في القانون الدولي و الجهود الدولية و الجزائرية ، رسالة ماجستير ،جامعة الجزائر 1 ، . 2007

ـ محياوي فاطمة ، حماية المنتجات المعدلة وراثيا ، رسالة ماجستير ، جامعة الجزائر 1 ، 2014 .

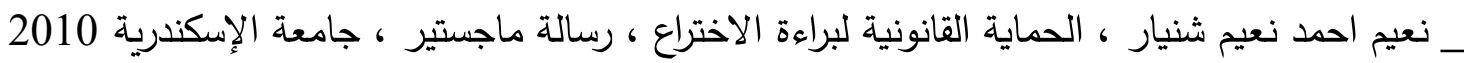


ـ بن عياد جليلة ، اختراعات العمال في اطار علاقة العمل ، اطروحة دكتوراه ، جامعة الجزائر 1، 2013 . ـ عمارة ضحى مصطفى ، حقوق الملكية الفكرية وحماية الأصناف النباتية الجديدة ، أطروحة دكتوراه جامعة المنوفية ، مصر ، 2011 ، 2010 ، .2011،

_ لحمر احمد ، النظام القانوني لحماية الابتكارات في القانون الجزائري ، أطروحة دكتوراه ، جامعة ابوبكر بلقايد ، تلمسان ، الجزائر . 2017 _ 2016 ،

ـ محمود مختار أحمد بريري ، الالتزام باستغلال المبتكرات الجديدة ، اطروحة دكتوراه ، مصر 1975 ، ص ص 30 ، 3010.

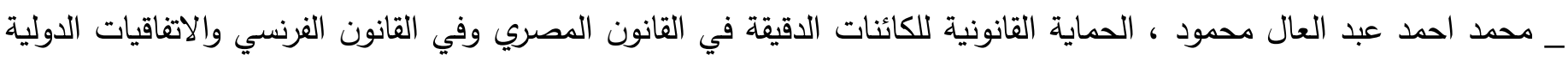
وفقا لآليات الملكية الفكرية ، أطروحة دكتوراه ، عين شس ، مصر 2012.

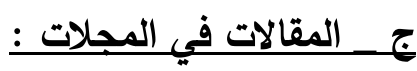

ـ دوار جميلة ، الحيازة النباتية وحقوق الملكية الفكرية في التشريع الجزائري ، مجلة البحوث العلمية في التشريعات البيئية ، 2016 ،

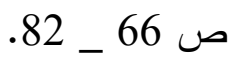
ـ خرخاش نادية ، تحليل وتتييم نظام براءات الاختراع الجزائري في ظل النصوص التشريعية والإجراءات الإدارية ، مجلة الاقتصاد والتتمية البشرية ، المجلد 9 العدد 2 ، جوان 2018 ، ص صن 139 _ 151. _ سميحة القليوبي ، النظام القانوني للاختراعات في جمهورية مصر العربية ، مجلة القانون و الاقتصاد للبحث في الثؤون القانونية و الاقتصادية ، العدد الأول ، السنة 39 ، مارس 1969.

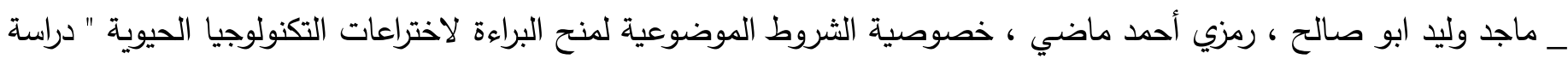
قانونية مقارنة " مجلة دراسات علوم الشريعة و القانون ، المجلد 43 ، ملحق 2 السنة 2016 من ص صل 977 إلى 989. ـ مزيان أبو بكر الصديق ، حقوق الملكية الفكرية على الأصناف النباتية المبتكرة في التثريع الجزائري ، مجلة الدراسات القانونية المقارنة ، المجلد 5 العدد 1 ، سنة 2019 ، ص صل 59 _ 71. ـ مصطفى كمال طهه ، الحماية القانونية لبراءات الاختراع في القانون المصري ، مجلة المحاماة السنة 52 العدد 3 ـ 4 ( مارسح أفريل )، 1989. المقالات بمواقع الانترنت :

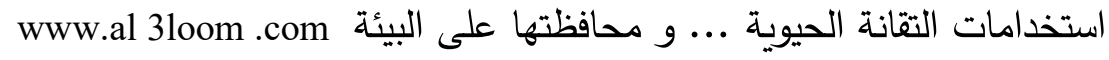

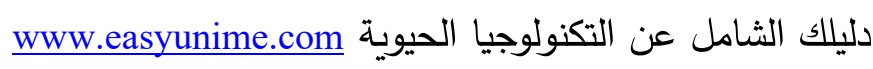
الملتقيات : دلث: بن عياد جليلة ، اختراعات التكنولوجيا الحيوية ، مداخلة ألقيت بأثغال الندوة الوطنية " دور التكنولوجيا الحيوية و الابداعات الدوائية في التتمية الاقتصادية بتاريخ 7 أكتوبر 2019 ، جامعة الجزائر 1. الكتب بالغة الأجنبية ,EDIK , Oran , 2003 ,p 42. Cherchour mustapha , propriété industrielle , première édition 